\title{
PARENTAL SUPPORT, MENTORING RELATIONSHIP AND 30-DAY PREVALENCE OF ALCOHOL USE AMONG HIGH SCHOOL BOYS AND GIRLS
}

\author{
Marianna Berinšterová, Monika Magdová, \& Miroslava Bozogáňová \\ Institute of Pedagogy and Psychology, Faculty of Humanities and Natural Sciences \\ University of Presov (Slovakia)
}

\begin{abstract}
Parental and nonparental significant adults are important developmental assets for adolescents. Previous studies confirm positive association of mentoring, parent-child relationship and substance use prevention. The aim of this paper is to explore a mediational effect of mentoring in relation to perceived paternal and maternal support and a 30-day prevalence of alcohol use among high school students in Slovakia.

Items from the ESPAD study were used for measuring the 30-day prevalence of alcohol use. The Resilience and Youth Development Module questionnaire was used and adapted for exploring the perceived support from the mother and the father. In addition, a single item measure for examining the existence of a mentoring relationship was used. 177 students (53.7\% girls; Mage=1.92; SD=1.69) participated in the research. Descriptive analysis and binary logistic regression were used for data analyses in SPSS 16. Analyses were conducted separately among boys and girls.

Out of the 177 students, 70 (39.5\%) reported the existence of a mentoring relationship and 113 students (63.8\%) reported alcohol use in the last 30 days. Results did not confirm significant mediational effect of a mentoring relationship on examined variables. Nevertheless, both the existence of a mentoring relationship and alcohol use in the last 30 days were more frequently found among boys who perceived a lower level of paternal and maternal support. Perceived paternal and maternal support were not significantly associated with the examined variables among girls.

Results point to different correlates of alcohol use depending on gender and also distinctions of significant parental and nonparental adult roles in the middle and late adolescents' development. Suggestions for counselling significant adults and adolescents are discussed.
\end{abstract}

Keywords: Significant adult, mentoring relationship, alcohol use, adolescents.

\section{Introduction}

A significant adult is an important protective factor against risky behaviour of adolescents (Galbo, 1986). Resilience theories claim that a supportive relationship from the adults in the child's environment serves as a developmental asset that leads to the satisfaction of the needs of autonomy, competence and relatedness (Constantine, Benard, Diaz, 1999).

Several authors suggest that gender-specific differences in parent-child relationships are less researched (Luk, Farhat, Iannotti, et al., 2010). Older research demonstrated that fathers provide more instrumental support and mothers affective support (Starrels, 1994). Gender correlates with parent-child relationships (Biblarz, Stacy, 2010). Positive association was also found between both mother-child and father-child communication and young people's life satisfaction (Levin, Currie, 2010). The attention of this field is justified in the context of substance use prevention because of confirmed gender-specific risk factors of substance use (Amaro, Blake, Schwartz, \& Flinchbaugh, 2001).

The adolescent's social world expands, including extrafamilial relationships (Arnett, 2004). A nonparental significant adult can act as a natural mentor (Rhodes \& Lowe, 2008). Positive consequences of mentoring were found in the areas of attitudes, health, relations - family bonding, school bonding, motivation, career outcomes, life skills, self-efficacy, school performance, and emotional regulation (Zand et al., 2009; Eby, Allen, Evans, Ng, \& DuBois, 2008; Jucovy, 2003).

Non-parental adults might have a functional role in which they provide support and guidance to others and serve as role models. Thus, individuals in different social roles, such as older friends, family members, but also romantic partners, might serve as a mentoring capacity to adolescents. 


\section{Objectives}

The aim of this paper is to explore a mediational effect of mentoring in relation to perceived paternal and maternal support and a 30-day prevalence of alcohol use among high school students in Slovakia. Previous research suggests gender-specific relationships between parental support and substance use of adolescents (Luk, Farhat, Iannotti, \& Simons-Morton, 2010).

\section{Methods}

\subsection{Research sample}

The sample consisted of 177 students (53.7\% girls; Mage=1.92; SD=1.69) from two high schools in Slovakia. The selection of schools was highly dependent on the willingness of school administrators to participate in the study. Data collection took place during school lessons, in the presence of an external administrator. Parental approval with school activities for the given school year has been extended to the participation in the research.

\subsection{Research questionnaire}

Data were collected by means of using the following items:

3.2.1. Single item measure of alcohol use in the last 30 days from the questionnaire of international study Espad (Hibell, Guttormsson, Ahlström, et al., 2011). Think back over the LAST 30 DAYS. On how many occasions (if any) did you drink alcohol? Responses were dichotomized: not at all (0), at least once.

\subsubsection{Single item measure for examining the existence of a mentoring relationship was} used, supplemented by a note about a mentoring relationship definition as follows. Mentoring relationship = this is a relationship between you and an adult who is not your parent or caretaker. He/she is someone you can go to if you need support, leadership and advice, someone who inspires you, encourages you to try your best in life.

Item was assessed on a two-point scale (yes - no).

3.2.3. RYDM questionnaire. Resilience and Youth Development Module questionnaire (Constantine, Benard, \& Diaz, 1999; Hanson \& Kim, 2007) was used and adapted for exploring the perceived support from the mother and the father. Parental support was understood as consisting of relationships perceived as caring, and include adults' high expectations (Constantine, Benard \& Diaz, 1999). Twenty-six items exploring parental support were assessed on a four-point Likert scale. Item examples include statements such as "My mother (father) really cares about me", "My mother (father) always wants me to do my best". The reliability (Cronbach $\alpha$ ) of the subscale in our sample was 0.955 .

\subsection{Statistical analysis}

Research data were processed by SPSS.16. Descriptive and regression analyses were used. For the needs of mediational analysis with dichotomic mediator and outcome variables, binary logistic regression was used. Sobel test (Herr, N. R. (n.d.)) determined value of Z-score. Analyses were conducted separately among boys and girls.

\section{Results}

\subsection{Descriptive analysis}

From the total sample of 177 respondents, 70 (39.5\%) reported the existence of a natural mentoring relationship. Out of 82 boys, 37 (45.1\%) reported the existence of a mentor. Out of 95 girls, $33(34.7 \%)$ reported the existence of a mentor. $(31.6 \%)$.

64 students $(36.2 \%)$ reported alcohol use in the last 30 days: 34 boys (41.5\%) and 30 girls 


\subsection{Mediational analysis in the sample of boys}

Two models for the sample of boys were conducted, examining maternal support (Figure 1) and paternal support (Figure 2) in relation to a 30-day prevalence of alcohol use with the mediational effect of mentoring. Boys with a higher level of perceived maternal and paternal support were more likely to report the existence of a mentoring relationship. Paternal support was also negatively associated with the 30-day prevalence of alcohol use. Sobel test for the Model $1(z=-0,764)$ and Model $2(z=-0,231)$ did not confirm significant mediational effects.

Figure 1. Mediational effect of a mentoring relationship in relation to maternal support and a 30-day prevalence of alcohol use among boys (Model 1).

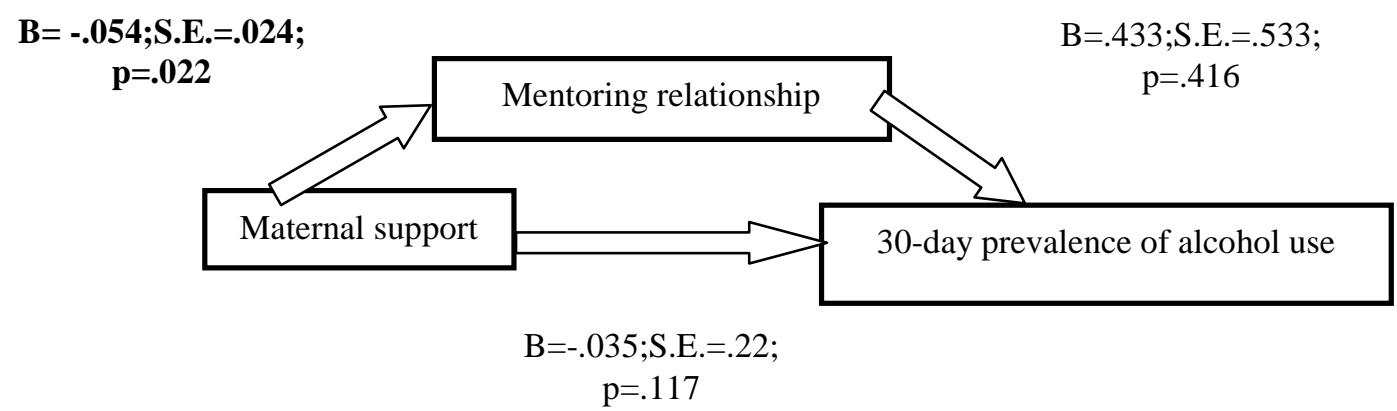

Figure 2. Mediational effect of a mentoring relationship in relation to paternal support and a 30-day prevalence of alcohol use among boys (Model 2.)

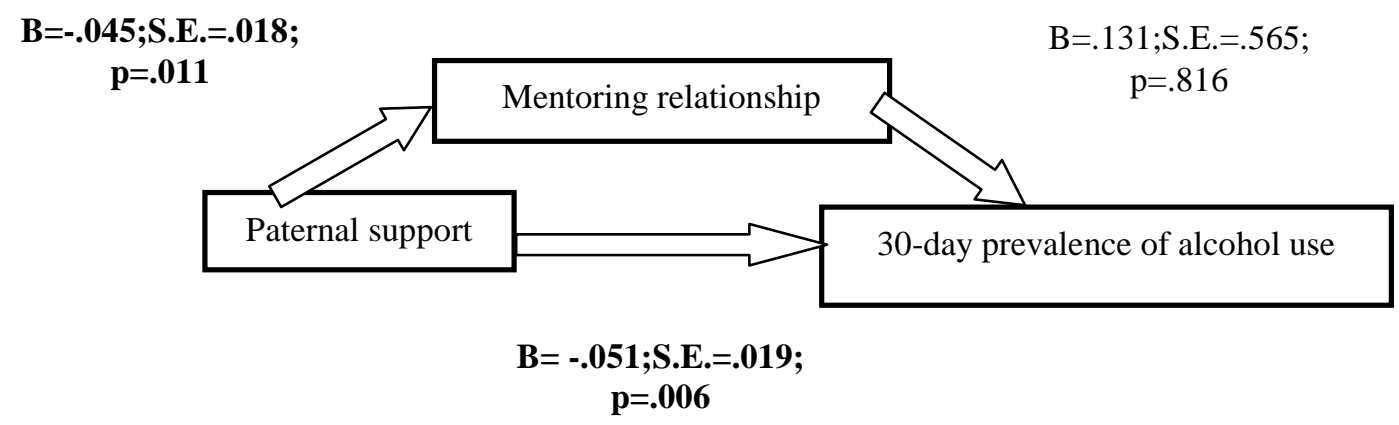

\subsection{Mediational analysis in the sample of girls}

Also, two models for the sample of girls were conducted examining maternal support (Figure 3) and paternal support (Figure 4) in relation to a 30-day prevalence of alcohol use with the mediational effect of mentoring. Associations between the variables were not significant. Sobel test for the Model 3 $(\mathrm{z}=-0,28)$ and Model $4(\mathrm{z}=-0,298)$ did not confirm significant mediational effects.

Figure 3. Mediational effect of a mentoring relationship in relation to paternal support and a 30-day prevalence of alcohol use among girls (Model 3).

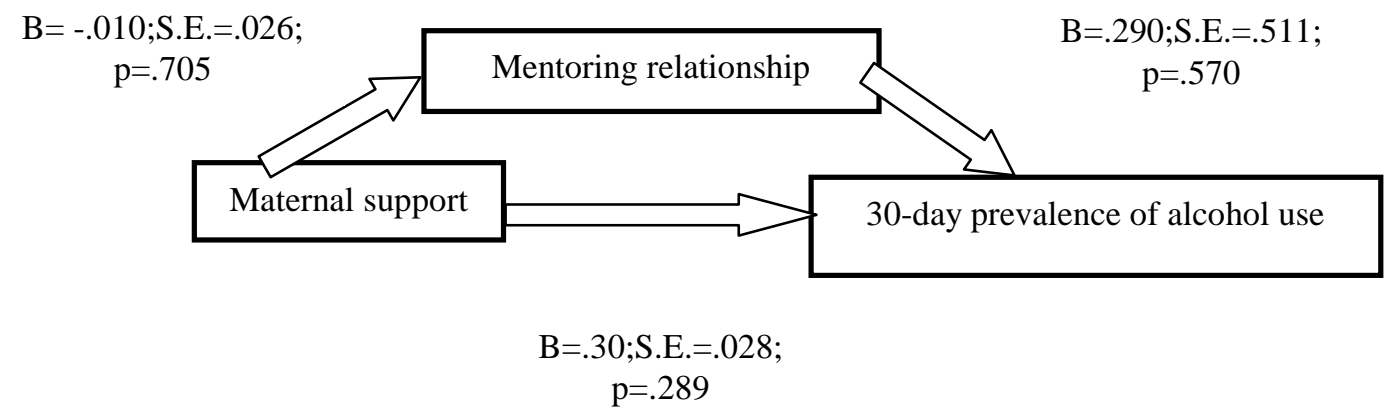


Figure 4. Mediational effect of a mentoring relationship in relation to paternal support and a 30-day prevalence of alcohol use among girls (Model 4).

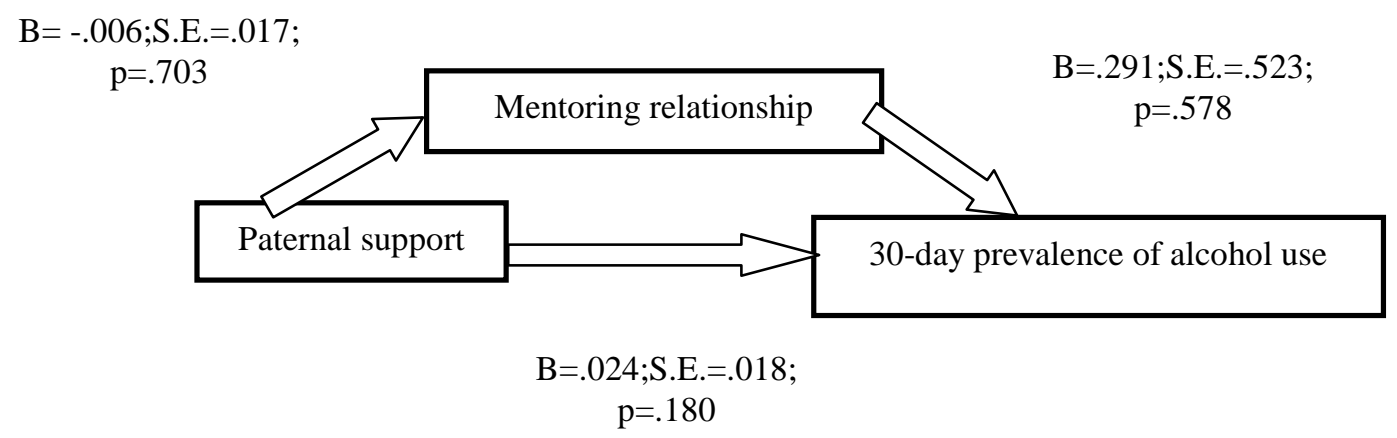

\section{Discussion and conclusion}

The aim of this paper was to explore a mediational effect of mentoring in relation to the perceived paternal and maternal support and a 30day prevalence of alcohol use among high school students in Slovakia. Although the Sobel test did not confirm a mediational effect, some significant associations were found, especially among boys:

- the association among the perceived maternal support and the existence of a mentor relationship, the perceived parental support and the existence of a mentoring relationship. Boys who perceived lower levels of paternal and maternal support were more likely to report a mentoring relationship. Among girls, this association was also negative but not significant

- The negative association between paternal support and the 30-day prevalence of alcohol use. Those boys who perceived lower levels paternal support were more likely to use alcohol in the last 30 days. This association was not significant for the maternal support. In contrast, previous research found that the fathers had less influence and were less involved in a relationship with the child than the mothers (Stoker \& Swadi, 1990, Williams \& Kelly, 2005).

No significant relationships among the variables was found among girls, in contrast with previous research which found that parental control and parental emotional support were more strongly related to substance use outcomes in girls than in boys, and also that girls were prone to supportive communication with their fathers (Choquet, Hassler, Morin, et al., 2008; Demidenko, Manion, Lee, 2015).

No significant association between a mentoring relationship and a 30-day prevalence of alcohol use was found, although relationships with a significant nonparental adult is considered to have multiple positive consequences. The explanation should be rooted in cultural and social norms. Alcohol use is considered a part of traditions and local social norms. It was found that descriptive norms are directly associated with alcohol use among students (Magdová, 2018).

\subsection{Limitations of the research}

Of course, this research has some limits, including the social desirability of answers, the sample size and also the limited amount of attention paid to the person of a mentor. Further research should focus on the socio-demographic, personality and social-psychology variables related to nonparental significant adults in the context of substance use.

The research suggests a protective role of parental support in the context of substance use. Resilience theory sees these developmental assets as a buffer against negative influences. The father-son relationship occupies a unique position. However, further research is needed to describe these genderspecific variations more closely. 


\section{References}

Amaro, H., Blake, S. M., Schwartz, P. M., \& Flinchbaugh, L. J. (2001). Developing theory-based substance abuse prevention programs for young adolescent girls. The Journal of Early Adolescence, 21(3), 256-293.

Arnett, J. J. (2004). A longer road to adulthood. Emerging adulthood, 3-25.

Biblarz, T. J., \& Stacey, J. (2010). How does the gender of parents matter? Journal of marriage and family, 72(1), 3-22.

Constantine, N., Benard, B., \& Diaz, M. (1999, June). Measuring protective factors and resilience traits in youth: The healthy kids resilience assessment. In: Seventh annual meeting of the Society for Prevention Research, New Orleans, LA.

Demidenko, N., Manion, I., \& Lee, C. M. (2015). Father-daughter attachment and communication in depressed and nondepressed adolescent girls. Journal of Child and Family Studies, 24(6), 1727-1734.

Eby, L. T., Allen, T. D., Evans, S. C., Ng, T., \& DuBois, D. L. (2008). Does mentoring matter? A multidisciplinary meta-analysis comparing mentored and non-mentored individuals. Journal of vocational behavior, 72(2), 254-26.

Galbo, J. J. (1986). Adolescents' perceptions of significant adults: Implications for the family, the school and youth serving agencies. Children and Youth Services Review, 8(1), 37-51.

Hanson, T. L., \& Kim, J. O. (2007). Measuring Resilience and Youth Development: The Psychometric Properties of the Healthy Kids Survey. Issues \& Answers. REL 2007-No. 34. Regional Educational Laboratory West.

Herr, N.R. (n.l.). Mediation with Dichotomous Outcomes. http://www.nrhpsych.com/mediation/logmed.html

Hibell, B., Guttormsson, U., Ahlström, S., Balakireva, O., Bjarnason, T., Kokkevi, A., \& Kraus, L. (2011). Substance use among students in 35 European countries. Stockholm: The Swedish Council for Information on Alcohol and Other Crugs (CAN).

Jucovy, L. (2003). Mentoring children of prisoners in Philadelphia. Public/Private Ventures. Retrieved November 12, 2017 from http://www.ppv.org/ppv/publications/assets/21_publication.pdf.

Levin, K. A., \& Currie, C. (2010). Family structure, mother-child communication, father-child communication, and adolescent life satisfaction: A cross-sectional multilevel analysis. Health Education, 110(3), 152-168.

Luk, J. W., Farhat, T., Iannotti, R. J., \& Simons-Morton, B. G. (2010). Parent-child communication and substance use among adolescents: Do father and mother communication play a different role for sons and daughters? Addictive behaviors, 35(5), 426-431.

Magdová Brutovská, M. (2018). Uloga društvenih normi u strukturnom modelu koji objašnjava uporabu alkohola među studentima. Društvena istraživanja: časopis za opća društvena pitanja, 27(4), 605-628.

Rhodes, J., \& Lowe, S. R. (2008). Youth mentoring and resilience: Implications for practice. Child care in practice, 14(1), 9-17.

Starrels, M. E. (1994). Gender differences in parent-child relations. Journal of family Issues, 15(1), 148-165.

Zand, D. H., Thomson, N., Cervantes, R., Espiritu, R., Klagholz, D., LaBlanc, L., \& Taylor, A. (2009). The mentor-youth alliance: The role of mentoring relationships in promoting youth competence. Journal of adolescence, 32(1), 1-17. 